\title{
Effect of workpiece sulphur content on the degradation of a PCBN tool material
}

\author{
J. Angseryd ${ }^{1,2 *}$, E. Olsson ${ }^{2}$, H.-O. Andrén ${ }^{2}$ \\ 1- R\&D Sandvik Tooling, SE-126 80 Stockholm, Sweden \\ (* jenny.angseryd@sandvik.com, +4687266632 ) \\ 2- Department of Applied Physics, Microscopy and Microanalysis group, Chalmers University of Technology, SE-412 96 Gothenburg, Sweden \\ (eva.olsson@chalmers.se and andren@chalmers.se)
}

\begin{abstract}
Tool degradation may be significantly different depending on small variations in chemical compositions of the workpiece material. The present study is an in-depth microstructure investigation of worn low content polycrystalline cubic boron nitride tool materials after dry hard turning of steels with low and high sulphur contents. The results illustrate the important role of sulphur content on the degradation of the crater zone. Sulphides tend to adhere on the wear surface and form layers that protect the tool from workpiece ingress. In the absence of sulphides in the workpiece material, no protective layer can form and iron compounds make their way into the tool microstructure already at lower cutting speeds $(150 \mathrm{~m} / \mathrm{min})$ and preferably attack cBN grains compared to $\mathrm{Ti}(\mathrm{C}, \mathrm{N})$ grains.
\end{abstract}

Keywords: PCBN: hard turning: wear: MnS: sulphide

\section{Introduction}

Hard turning operations with polycrystalline cubic boron nitride (PCBN) tools have several advantages compared to grinding operations in machining of hardened steels. Hard turning leads to reduced costs by an overall time reduction in concerned production steps as well as better surface finish and is more environmentally friendly by avoiding cutting fluids. PCBN cutting tool materials has proven to be an appropriate choice in this specific field.

The main wear mechanisms discussed in hard turning with PCBN tool materials are abrasion, adhesion and chemical or diffusion wear [1-2]. Many factors influence the wear mechanisms of the tool material in hard turning. Machining parameters like speed, feed, depth of cut are important as well as tool geometry but also the chemical composition of both the PCBN tool material and the workpiece material [3-4]. Low content PCBN materials (45-65 vol\% cBN) commonly consist of $\mathrm{cBN}$ grains in a ceramic matrix. The major matrix phase is often a Tibased compound, such as $\mathrm{TiC}, \mathrm{TiN}$ or $\mathrm{Ti}\left(\mathrm{C}_{\mathrm{x}}, \mathrm{N}_{1-\mathrm{x}}\right)$. The range of workpiece materials is wide and includes many chemical compositions and thus microstructures of hardened steels with different carbides, oxides and inclusions.

Sulphide inclusions play an important role in machining of steels, not only with PCBN tools. It is known that sulphide inclusions are more ductile than the rest of the steel matrix and can thus act as chip-breaking-points during machining [5].

It has been shown that sulphide inclusions from the workpiece material can adhere to cemented carbide cutting edges in machining, where $\mathrm{MnS}$ is found [6-7]. It has also been

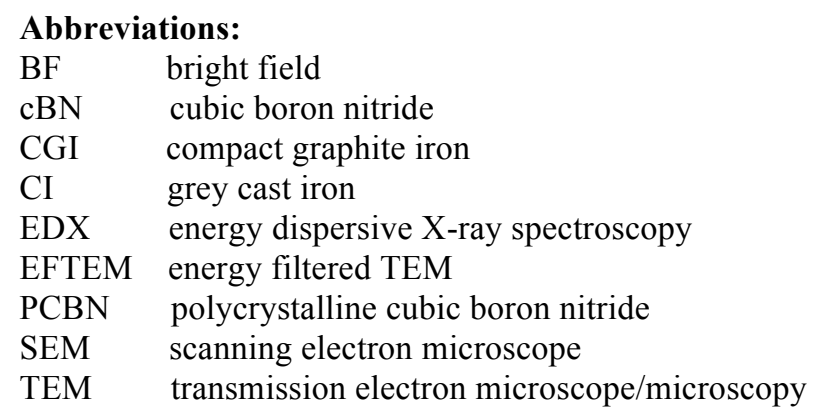


described that inclusions can be sliced off and smeared out in tool/chip interfaces in machining operations. The sulphide inclusions are found to be chemically stable at average cutting temperatures, without any signs of dissociation, however at higher cutting speeds and higher cutting temperatures the action of sulphides tends to disappear as the adhered layer decreases. This has led to the question whether sulphide layers could be stable in the contact zone at lower cutting speeds in machining and thus prevent iron deposition but lose their stability at higher temperatures with an increase in iron deposition as a result [8-10]. Investigation of PCBN tool wear [11] when machining compact graphite iron (CGI) and grey cast iron (CI) also showed that the degradation is depending on a MnS layer to form on the tool cutting edge. The formation of this layers and its positive impact on degradation is presented to be the reason to why sulphide containing CI materials are more machinable than CGI.

A built-up layer or adhered layer is often observed and discussed for machining with PCBN tools [12-18]. This layer is most commonly analysed with EDX by point analysis on the cutting edge. The purpose of this study is to contribute to the knowledge of how fundamental machining mechanisms can be investigated and visualised with in-depth microstructure investigations. The present study is an investigation of what impact a small variation of the chemical composition, i.e. sulphur content, in the workpiece material has on the degradation mechanisms active in crater wear of low content PCBN cutting tools.

\section{Experimental methods}

\subsection{Tool and workpiece material}

The investigated tool material (in the form of CNGA 120412 inserts) used in the turning operation was a low content PCBN tool material. The microstructure contains $\sim 55 \mathrm{vol} \% \mathrm{cBN}$ grains in a complex ceramic matrix consisting of primarily $\operatorname{Ti}(\mathrm{C}, \mathrm{N})$ and $\mathrm{Al}_{2} \mathrm{O}_{3}$. This tool material has been extensively studied before [19-20]. Two types of steel (A and B) were used as workpiece materials with compositions presented in table 1. The steels were in the form of rods and both obtained from the same steel-maker (Ovako Steel). The difference in composition primarily lies in the sulphur content as table 1 shows. The rods were all case hardened to $\sim 63 \mathrm{HRC}$ (table 2) and the hardness was measured before every test.

\subsection{Experimental procedure - turning test}

Identical dry hard turning tests were performed on both steels. The length of the steel rods was $400 \mathrm{~mm}$ and the cutting time for one pass was approximately $180 \mathrm{~s}$. A speed of 150 $\mathrm{m} / \mathrm{min}$ was used with a feed of $0.2 \mathrm{~mm} / \mathrm{rev}$ and a cutting depth of $0.15 \mathrm{~mm}$. Two times two tests were performed for each workpiece material type. The first type of test was one pass and the second type of test was three passes of the PCBN insert over the steel rods. Figure 1 shows the setup for the machining test.

\subsection{Characterisation methods}

All machined PCBN inserts were investigated with a Leo Ultra 55 field emission gun SEM equipped with an Oxford Inca EDX system. EDX mapping was performed on the crater regions by tilting the analysed area towards the EDX detector. EDX maps were obtained from the following lines in the EDX spectrum: $\mathrm{B} \mathrm{K}_{\alpha 1,2}, \mathrm{C} \mathrm{K}_{\alpha 1,2}, \mathrm{~N} \mathrm{~K}_{\alpha 1,2}, \mathrm{O} \mathrm{K}_{\alpha 1}$, Ti K $\mathrm{K}_{\alpha 1}, \mathrm{Cr} \mathrm{K}_{\alpha 1}, \mathrm{Mn}$ $\mathrm{K}_{\alpha 1}, \mathrm{Fe} \mathrm{K}_{\alpha 1}, \mathrm{Al} \mathrm{K}_{\alpha 1}, \mathrm{~W} \mathrm{~L}_{\alpha 1}$ and $\mathrm{S} \mathrm{K}_{\alpha 1}$. Problem with overlap of Ti/N and $\mathrm{Cr} / \mathrm{Mn}$ lines in EDX are acknowledged and taken into consideration for the evaluation. Additional and 
complementary information concerning the distribution of the different elements was obtained using EFTEM in TEM. Thin specimens were then produced by an in-situ lift-out technique in a FEI Strata 235 Dual Focused Ion Beam SEM, described more in detail in earlier work [6, 21]. The technique includes $\mathrm{Ga}$ ion milling to remove material and cut out $\sim 5 \times 40 \times 15 \mu \mathrm{m}$ specimens, which are lifted out with a micromanipulator and placed on small Cu-grids. With this technique, thin specimens were taken from across the crater on the rake face and thinned down into TEM foils (with relative thickness $(\mathrm{t} / \lambda)<0.6, \mathrm{t}=$ thickness and $\lambda=$ electron mean free path). Specimens were produced from one PCBN tool material machined in material A (high sulphur content) and another PCBN tool machined in material B (low sulphur content), both after 3 passes. The foils were investigated in a FEI Titan 80-300 FEG TEM with a Gatan Tridiem 866 image filter system operated at an acceleration voltage of $300 \mathrm{kV}$. EFTEM elemental maps were obtained from the following edges; $\mathrm{B}$ (K-edge), $\mathrm{C}$ (K-edge), $\mathrm{O}$ (Kedge), Mn ( $\mathrm{L}_{2,3}$-edge), Al (K-edge), $\mathrm{N}$ (K-edge), Ti ( $\mathrm{L}_{2,3}$-edge), Fe ( $\mathrm{L}_{2,3}$-edge) and $\mathrm{S}\left(\mathrm{L}_{2,3^{-}}\right.$ edge).

\section{$3 \quad$ Results}

Differences in chip formation behaviour were observed during the machining tests. The chips were broken into smaller pieces when material A (high sulphur content) was machined, while long chips were formed when material B (low sulphur content) was machined. The flank wear (VB) and crater depth was measured with an optical microscope as well as the hardness, seen in table 2. Only small variations, with a slightly deeper crater for the test cut in Material B, are seen between the tests with the two workpiece materials.

\subsection{SEM and EDX results}

Figure 2 shows SEM micrographs from the crater region on the rake face from different tests after one pass and after three passes. It can be seen that the crater width increases with the number of passes, i.e. with increased interaction time between tool and workpiece material. Comparisons are also made between PCBN tools machined in material A (high sulphur content) and B (low sulphur content) after one or three passes. It is observed that the crater shape is slightly different both after one pass and three passes. After machining material A the PCBN tools show an uneven edge in the back of the crater. Otherwise the overall crater size appears to be somewhat similar.

SEM investigations show an adherent layer on both the rake face and flank face, see figure 2 . Built-up layers and scattered areas are seen close to the crater edges and on areas beyond the crater on the rake face. More built-up layers are observed on tools from test with material A (high sulphur content). Theses built-up layers and scattered areas decrease with increased interaction time.

SEM/EDX mapping was performed on the rake face, with its formed crater, for all the tested PCBN inserts. Examples of analysis results are presented in figure 2. EDX maps from elements present in the PCBN material can be seen in the B, and Ti maps. EDX maps from workpiece material elements can be seen in the $\mathrm{O}, \mathrm{Fe}, \mathrm{Mn}$ and $\mathrm{S}$ maps. These maps show the distribution of the adhered layer on the rake face.

If EDX mapping results are compared it is observed that a higher iron signal is obtained in the crater region for PCBN tools after machining Material B (low sulphur content) both after one pass and after three passes. The iron signal is nicely confined to the crater as seen in figures 
$2 b$ and $d$. Iron is also found on the tools after machining material A (high sulphur content) but it is more localised to the crater edges as seen in figures $2 a$ and $c$. The oxygen maps show oxidised regions of the adherent layer. Sulphur is found in the whole crater region on the tools after machining material A where it coincides with manganese signal (figures $2 a$ and $c$ ). Manganese is found on the crater edge regions off PCBN tools after machining Material B where it often coincides with oxygen figures $2 b$ and $d$.

It can also be observed that almost no boron, from cBN, can be observed in the crater in figures $2 b$ and $d$, from the PCBN tool after machining material B (low sulphur content), compared to figures $2 a$ and $c$, from the tool after machining material A (high sulphur content) where $\mathrm{B}$, from $\mathrm{cBN}$, is detected in the crater.

\subsection{TEM and EFTEM results}

\subsubsection{Results from machining test with material A (high sulphur content)}

The TEM study of specimens taken from the PCBN inserts after machining workpiece material A (high sulphur content), show several characteristic features. EFTEM elemental maps were obtained from different areas and for the different elements. Some examples are presented in figures 3-5. Mn and S areas are commonly found as features at the wear surface, see $\mathrm{Mn}$ and $\mathrm{S}$ elemental maps in figures 3 and 4. These areas are often elongated and look as if they were smeared on the surface. $\mathrm{Mn}$ and $\mathrm{S}$ areas are frequently found close or closest to the wear surface. Iron-rich features are also found on the wear surface. These iron-rich areas are often oxidised as for example seen in the $\mathrm{Fe}$ and $\mathrm{O}$ elemental maps in figure 5. It is also observed that some oxidised iron-rich areas contain Mn (Mn elemental map figure 5).

Another observation is that $\mathrm{cBN}$ grains on the wear interface tends to have a concave shaped wear surface (for example seen in figure 4) while Ti(C,N) grains on the wear surface tends to have more flat or even convex phase boundaries (for example seen in figure 5). In addition, it is often found that $\mathrm{cBN}$ grains are more worn if compared to neighbouring $\mathrm{Ti}(\mathrm{C}, \mathrm{N})$ grains.

\subsubsection{Results from machining test with material B (low sulphur content)}

Some of the TEM/EFTEM results from the PCBN tool material after machining the workpiece material B (low sulphur content) are presented in figure 6-7. The results show that iron-rich features have made their way into the PCBN tool material, below the actual wear surface. It appears as though the penetrating material is primarily surrounded by $\operatorname{Ti}(\mathrm{C}, \mathrm{N})$ grains. Figures 6 and 7 clearly portrait this, where iron-rich features can be seen below $\mathrm{Ti}(\mathrm{C}, \mathrm{N})$ grains present on the wear interface. In fact, it appears as if $\mathrm{Ti}(\mathrm{C}, \mathrm{N})$ grains stand proud of iron-rich features while $\mathrm{cBN}$ grains are missing.

If the wear surface is studied closer it is observed that it mainly consists of $\mathrm{Ti}(\mathrm{C}, \mathrm{N})$ grains and only occasional cBN grains are found on the actual wear surface. $\mathrm{cBN}$ grains that are observed show similar "concave like" appearances as from the test with material A (high sulphur content). The $\operatorname{Ti}(\mathrm{C}, \mathrm{N})$ grains found on the wear interface itself show "flat and convex type" appearances as from the test with material A. When the wear surfaces of the grains of respective phase are studied below the wear surface, the shape is changed. Figure 6 (which is colour coded in figure 8c) shows an example where the $\mathrm{cBN}$ grain in the centre is attacked by a iron-rich feature. The wear surface of that $\mathrm{cBN}$ grain is uneven as seen in both the $\mathrm{B}$ and $\mathrm{N}$ elemental maps. $\mathrm{Ti}(\mathrm{C}, \mathrm{N})$ wear surface below the wear interface are not uneven. Figure 7 
shows several smaller $\mathrm{Ti}(\mathrm{C}, \mathrm{N})$ grains in contact with a penetrating iron-rich feature which look more or less smooth, even though small signs of interaction can be observed.

\section{Discussion}

\subsection{Degradation behaviour on a macroscopic level}

It is known that sulphides in steel workpiece materials have an impact on the breaking of chips, i.e. the chip breaks into smaller pieces with sulphides present. This phenomenon was thus expected to take place in the present study. In fact the chip formation during machining of the workpiece material A (high sulphur content) was seen as small chip pieces breaking of, while long pieces were formed during the machining process of the workpiece material $\mathrm{B}$ (low sulphur content).

Only minor differences are seen in measured flank face wear (VB), crater depth and crater size on the machined PCBN tools for both materials A and B. SEM/EDX results from the crater regions showed workpiece material elements present in the crater and neighbouring regions. More built-up layers were found on the tools after machining material A (high sulphur content). This can be coupled to the capability of sulphides to adhere on cutting tool edges. This also agrees well with the observation that $\mathrm{S}$ and $\mathrm{Mn}$ areas were found in the whole crater area on the tools after machining material A. It was also evident that more iron was present in the crater regions of tools after machining material B (low sulphur content), which was confirmed in the cross-section study by TEM/EFTEM. SEM/EDX analysis also showed less $\mathrm{B}$ signal from $\mathrm{cBN}$ grains in the crater on the tool after machining material $\mathrm{B}$, which can be coupled to the EFTEM results showing a more or less $\mathrm{cBN}$ depleted zone closest to the wear surface. More $\mathrm{B}$ signal from $\mathrm{cBN}$ was thus observed with EDX for the tools after machining material $\mathrm{A}$, where TEM/EFTEM analysis showed $\mathrm{cBN}$ grains in the actual wear surface.

\subsection{Degradation behaviour on the micro- and nanoscopic level}

This study shows similar degradation behaviours to those recognised in earlier studies [6-7] where another workpiece material geometry as well as a slightly lower workpiece material hardness were used and where both studies included workpiece materials with higher sulphur contents. In the first of the previous studies [6], the same cutting speed, depth and feed was used as in the present investigation. Results from this study showed unexpectedly high frequency of $\mathrm{Mn}$ and $\mathrm{S}$ areas close and closest to the wear interface. cBN grains and $\operatorname{Ti}(\mathrm{C}, \mathrm{N})$ grains showed wear interfaces resembling those found in the present study with concave and convex shapes, respectively. The later paper [7] was a study of the impact of a higher cutting speed, where the most important observation was that iron-rich areas penetrated the PCBN tool material and primarily attacked $\mathrm{cBN}$ grains. The present study shows that the degradation behaviour changes when the chemical composition of the workpiece material changes, i.e. a variation of the sulphur content, see figure 8. With higher content of sulphur in the workpiece material (material A) the wear behaviour show correlations with the earlier study [6], however when the workpiece material has a low sulphur content (material B) the wear behaviour instead resembles that of the findings found in the other study done with a higher cutting speed [7]. With low sulphur content in the workpiece material the PCBN tool is more aggressively worn and iron-rich features make their way into the tool itself, see figure 8. As the earlier studies also show, cBN appears to be primarily degraded compared to $\operatorname{Ti}(\mathrm{C}, \mathrm{N})$ independently of the cutting speeds tested or if sulphide inclusions are present in the 
workpiece material or not. $\operatorname{Ti}(\mathrm{C}, \mathrm{N})$ appears to degrade in the same way no matter if sulphur is present in the workpiece material or not.

\subsection{Impact of degradation mechanism on the crater formation}

The present study shows two different wear mechanisms for the PCBN tool depending on the chemical composition of the workpiece material, i.e. variations of the sulphur content. It is shown that when sulphide inclusions are present in the workpiece material it tends to smear the wear interface in the crater. When the amount detected on the wear interface is compared to the content in the workpiece material it is clear that sulphides are somehow favoured to stay in this region. The smeared sulphides on the wear surface can act as a lubricant and decrease friction. In addition, the chips are easily removed from the cutting zone since they break into small pieces. Without sulphides to reduce friction a possible degradation scenario can be discussed. A higher friction means a higher temperature which can explain the penetration of iron-rich features into the PCBN tool. This can also explain why the degradation behaviour resembles that of an increased cutting speed, where the cutting temperature also increases. However, even though two degradation mechanisms were identified only slight differences were observed on the overall tool wear. These tests were perhaps too short to grasp the complete impact of the different mechanisms. One can imagine an increased risk of chipping if one major phase, $\mathrm{cBN}$, is depleted in the region closest to the wear surface and replaced by penetrating iron-rich features. At some point the stress may be too high for this configuration to hold together and fracturing might take place.

The temperature and pressure in the contact zone on the cutting edge evidently has a significant impact on the plasticity of sulphides as well as their lubricating effect. The protective role of the sulphide from iron penetration decreases with increasing temperature caused by for example a higher cutting speed. In the absence of sulphur in the workpiece material the protective sulphide layer on the crater is missing and iron can thus penetrate the tool material at lower cutting speeds.

\section{Conclusions}

The present study shows how sulphur in the workpiece has an impact on the wear behaviour of PCBN tools. Sulphides tend to enrich on the wear surface of the PCBN tool crater region and acts as a protective layer towards iron. When sulphides are absent in the workpiece material more severe degradation takes place in the crater, where iron-rich features penetrate the microstructure of the tool material. $\mathrm{cBN}$ grains are more affected compared to $\operatorname{Ti}(\mathrm{C}, \mathrm{N})$ grains both with and without the protective layer. However, when the protective layer is absent cBN grains are considerably more aggressively attacked compared to when the protective layer is present.

\section{Acknowledgments}

The authors would like to thank Ulf Oscarsson and Jorge Canales for performing the turning tests. This work was carried out with the financial support by Sandvik Tooling and the Swedish Research Council. Financial support for expensive equipment, e.g. the Titan TEM, from the Knut and Alice Wallenberg Foundation, the Swedish Research Council (VR) and Chalmers University is also gratefully acknowledged. 


\section{References}

1. Y. Huang and S.Y. Liang, Modelling of CBN tool flank wear progression in finish hard turning Journal of Manufacturing Science and Engineering, Transactions of the ASME. 126 (2004) 98-106

2. Y. Huang and S.Y. Liang, Modelling of CBN tool crater wear in finish hard turning, International Journal of Advanced Manufacturing Technology 24 (2004) 632-639

3. K.Y. Chou and C.J. Evans, Tool wear mechanism in continuous cutting of hardened tool steels, Wear. 212 (1997) 59-65.

4. K.Y. Chou, C.J. Evans, and M.M. Barash, Experimental investigation on cubic boron nitride turning of hardened AISI 52100 steel, Journal of Materials Processing Technology. 134 (2003) 1-9.

5. H.S. Qi and B. Mills, On the formation mechanism of adherent layers on a cutting tool, Wear. 198 (1996) 192-196.

6. J. Angseryd, E. Coronel, M. Elfwing, E. Olsson, and H.-O. Andrén, The microstructure of the affected zone of a worn PCBN cutting tool characterised with SEM and TEM, Wear. 267 (2009) 1031-1040.

7. J. Angseryd and H.-O. Andrén, An in-depth investigation of the cutting speed impact on the degraded microstructure of worn PCBN cutting tools, Accepted for publication in Wear.

8. A. Nordgren and A. Melander, Deformation behaviour of different types of inclusion during chip formation in turning of quenched and tempered steels, Materials Science and Technology. 5 (1989) 940-951.

9. G. Poulachon, M. Dessoly, J.L. Lebrun, C. Le Calvez, V. Prunet, and I.S. Jawahir, Sulphide inclusion effects on tool-wear in high productivity milling of tool steels, Wear. 253 (2002) 339-356.

10. G. Bittès, F. Leroy, and G. Auclair, The relationship between inclusionary deposits and the wear of cutting tools, Journal of Materials Processing Tech. 54 (1995) 88-96

11. M. Gastel, C. Konetschny, U. Reuter, C. Fasel, H. Schulz, R. Riedel, and H.M. Ortner, Investigation of the wear mechanism of cubic boron nitride tools used for the machining of compacted graphite iron and grey cast iron, International Journal of Refractory Metals and Hard Materials. 18 (2000) 287-296.

12. J. Barry and G. Byrne, Cutting tool wear in the machining of hardened steels Part II: cubic boron nitride cutting tool wear, Wear. 247 (2001) 152-160.

13. S.Y. Luo, Y.S. Liao, and Y.Y. Tsai, Wear characteristics in turning high hardness alloy steel by ceramic and CBN tools, Journal of Materials Processing Technology 88 (1999) 114-121.

14. J.P. Costes, Y. Guillet, G. Poulachon, and M. Dessoly, Tool-life and wear mechanisms of CBN tools in machining of Inconel 718, International Journal of Machine Tools \& Manufacture 47 (2007) 10811087.

15. S.A. Klimenko, Y.A. Mukovoz, V.A. Lyashko, A.N. Vashchenko, and V.V. Ogorodnik, On the wear mechanism of cubic boron nitride base cutting tools, Wear. 157 (1992) 1-7.

16. S. Takatsu, H. Shimoda, and K. Otani, Effects of CBN Content on the Cutting Performance of Polycrystalline CBN Tools, International Journal of Refractory Metals and Hard Materials. 2 (1983) 175-178.

17. H.M. Lin, Y.S. Liao, and C.C. Wei, Wear behaviour in turning high hardness alloy steel by CBN tool, Wear. 264 (2008) 679-684.

18. C. Lahiff, S. Gordon, and P. Phelan, PCBN tool wear modes and mechanisms in finish hard turning, Robotics and Computer-Integrated Manufacturing 23 (2007) 638-644.

19. J. Angseryd, M. Elfwing, E. Olsson, and H.-O. Andrén, Detailed microstructure of a cBN based cutting tool, International Journal of Refractory Metals and Hard Materials. 27 (2009) 249-255

20. J. Angseryd, M. Albu, H.-O. Andrén, and G. Kothleitner, A quantitative analysis of a multi-phase polycrystalline cubic boron nitride tool material using DualEELS, Accepted for publication in Micron, http://dx.doi.org/10.1016/j.micron.2011.02.006.

21. J. Angseryd, Microstructure of a cubic boron nitride tool material and its degradation during hard turning operations, in ISBN 978-91-7385-488-7, Chalmers University of Technology: Gothenburg. 


\section{Tables}

Table 1. The chemical composition, in wt $\%$, of the two workpiece materials, A (high sulphur content) and $B$ (low sulphur content), as given by the supplier (balance Fe).

\begin{tabular}{|c|c|c|c|c|c|c|c|c|c|c|c|}
\hline Material & $\mathbf{C}$ & $\mathbf{S i}$ & $\mathbf{M n}$ & $\mathbf{P}$ & $\mathbf{S}$ & $\mathbf{C r}$ & $\mathbf{N i}$ & $\mathbf{M o}$ & $\mathbf{C u}$ & $\mathbf{V}$ & $\mathbf{A l}$ \\
\hline A & 0.14 & 0.11 & 1.26 & 0.006 & 0.022 & 2.16 & 0.48 & 0.47 & 0.170 & 0.160 & 0.028 \\
\hline B & 0.15 & 0.25 & 1.24 & 0.009 & 0.001 & 2.16 & 0.46 & 0.45 & 0.120 & 0.180 & 0.034 \\
\hline
\end{tabular}

Table 2. Flank face wear (VB), crater depth and hardness (HRC) measured on the PCBN tools machined in Material A (high sulphur content) and Material B (low sulphur content) after one, two and three passes.

\begin{tabular}{lccclccc|} 
Material A & 1 pass & 2 passes & 3 passes & Material B & 1 pass & 2 passes & $\mathbf{3}$ passes \\
VB $[\mu \mathrm{m}]$ & 53 & 69 & 83 & VB $[\mu \mathrm{m}]$ & 46 & 65 & 83 \\
Crater depth $[\mu \mathrm{m}]$ & 104 & 109 & 134 & Crater depth $[\mu \mathrm{m}]$ & 88 & 113 & 139 \\
HRC before & 63.4 & - & - & HRC before & 63.5 & - & - \\
HRC after & - & - & 63.2 & HRC after & - & - & 63.3 \\
\hline
\end{tabular}




\section{Figures}

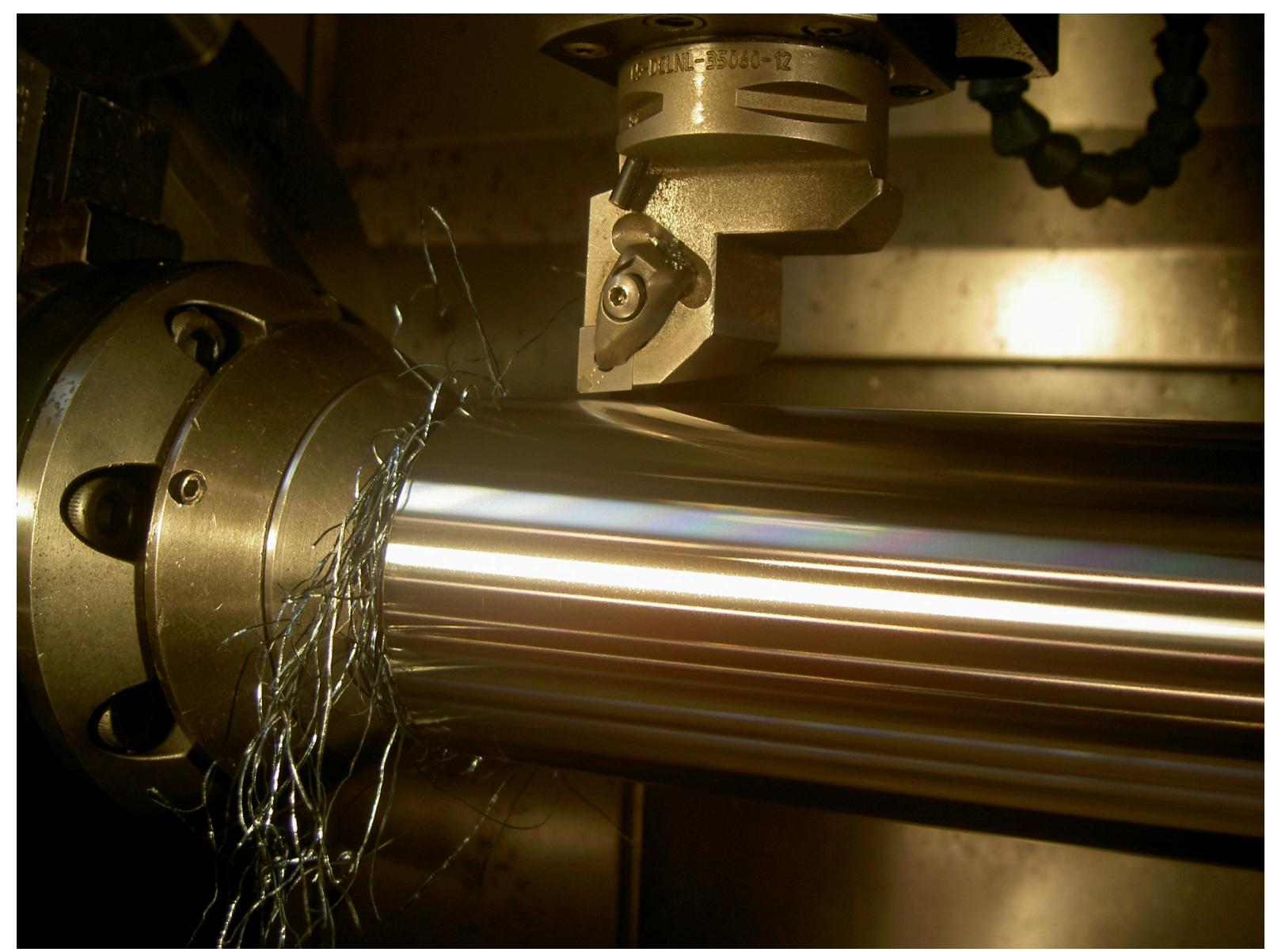

Figure 1. Setup for the dry hard turning test. 

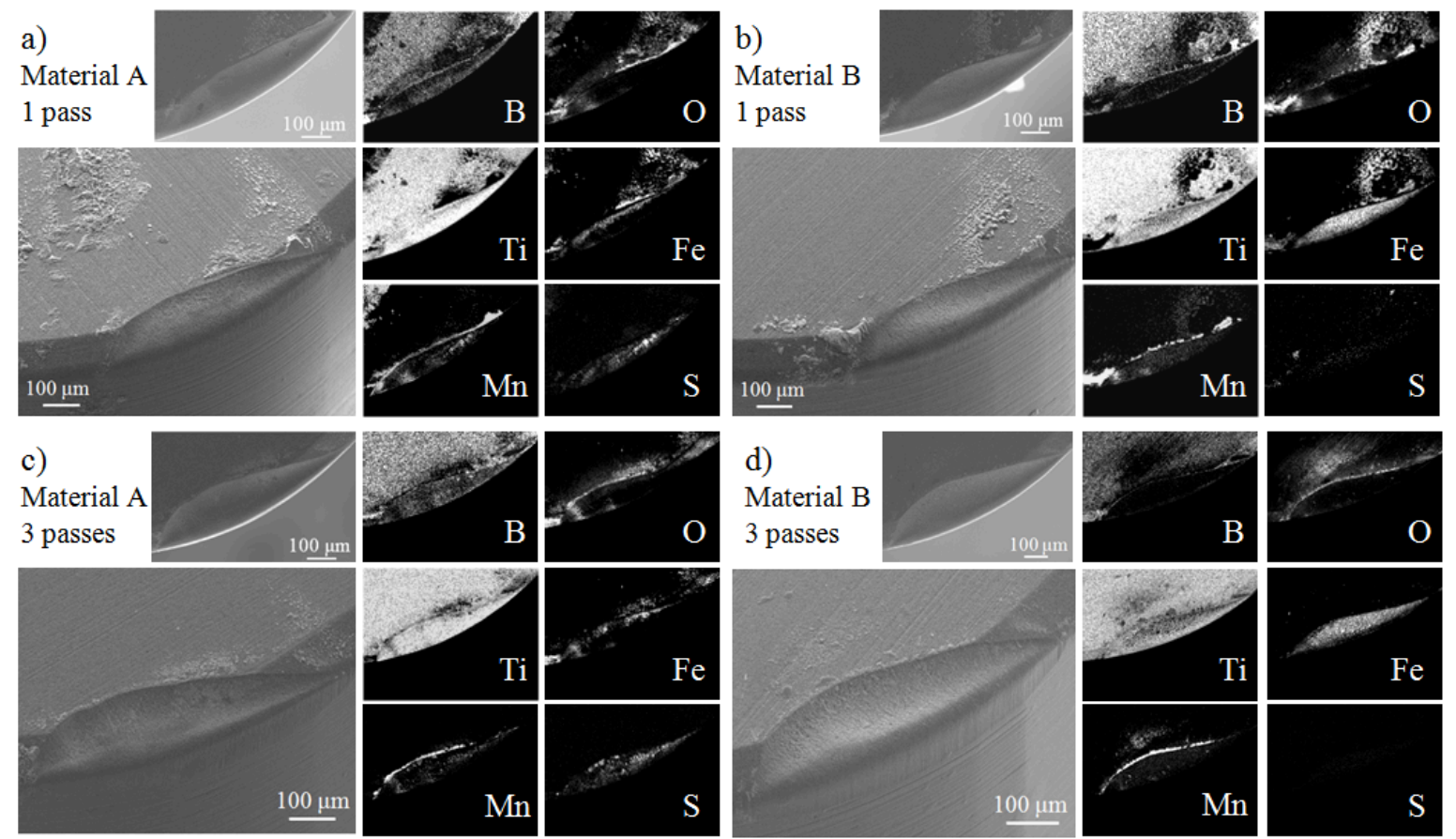

Figure 2. SEM micrographs from worn PCBN cutting edges from the side (large micrograph) and from the top view (small micrograph) also analysed with EDX mapping. a) Results from a PCBN cutting edge machined in Material A (high sulphur content) after one pass with SEM micrographs and EDX maps from B, O, Ti, Fe, Mn and S. b) Results from a PCBN cutting edge machined in Material B (low sulphur content) after one pass with SEM micrographs and EDX maps from B, O, Ti, Fe, Mn and S. c) Results from a PCBN cutting edge machined in Material A (high sulphur content) after three passes with SEM micrographs and EDX maps from B, O, Ti, Fe, Mn and S. d) Results from a PCBN cutting edge machined in Material B (low sulphur content) after three passes with SEM micrographs and EDX maps from B, O, Ti, Fe, Mn and S. 

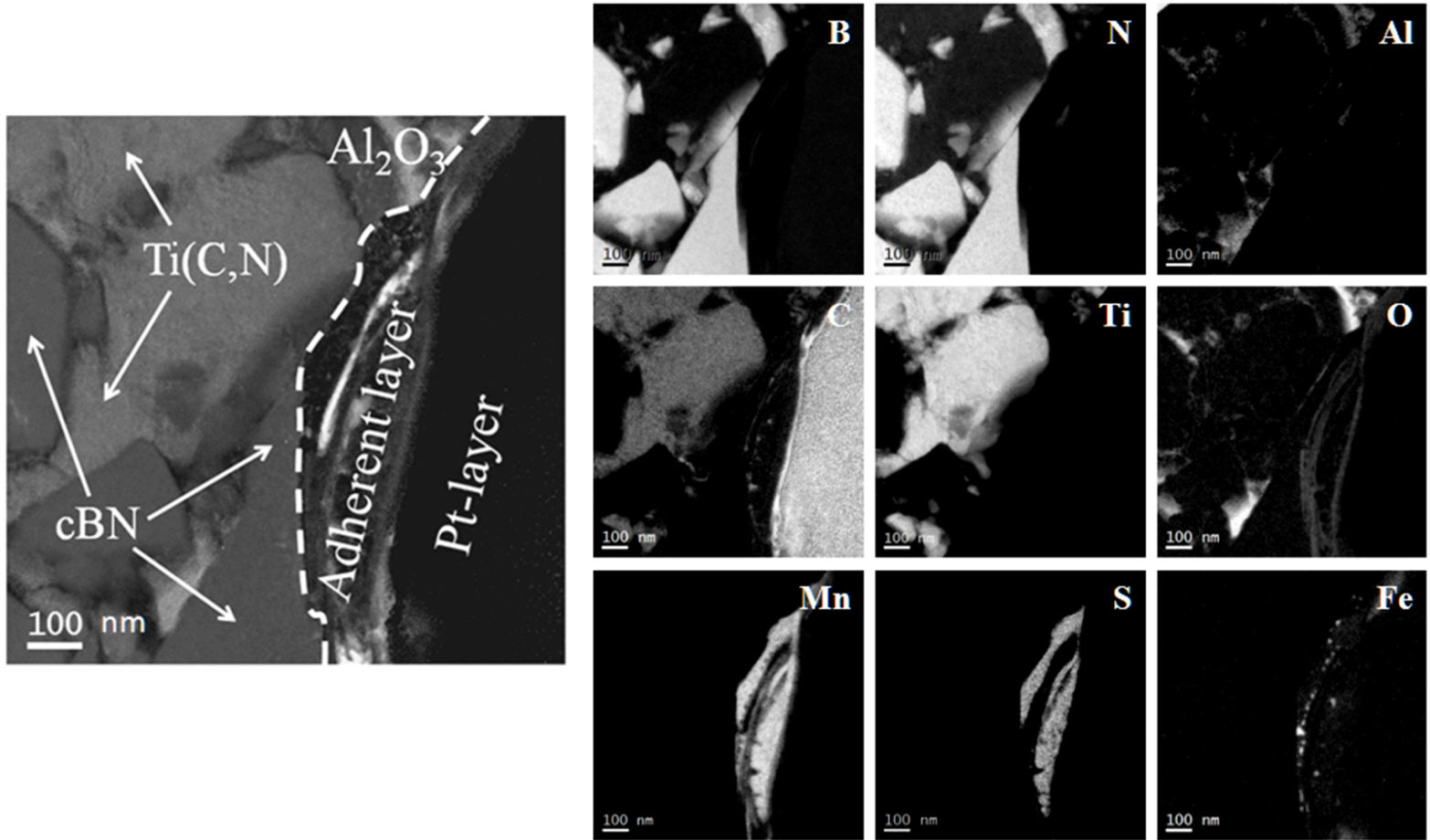

Figure 3. Some phases are indicated in the combined TEM/EFTEM micrograph, to the left, as well as the wear surface towards the adherent layer and parts of the protective Pt-layer from the specimen preparation. The EFTEM elemental maps, to the right, are from a PCBN insert run in workpiece material A (high sulphur content) for B (K-edge), C (K-edge), O (K-edge), Mn ( $\mathrm{L}_{2,3}$-edge), Al (K-edge), $\mathrm{N}$ (K-edge), Ti ( $\mathrm{L}_{2,3}$-edge), Fe $\left(\mathrm{L}_{2,3}\right.$-edge and $\mathrm{S}\left(\mathrm{L}_{2,3}\right.$-edge). A large $\mathrm{Mn}$ and $\mathrm{S}$ area can be seen in the $\mathrm{Mn}$ and $\mathrm{S}$ elemental maps.
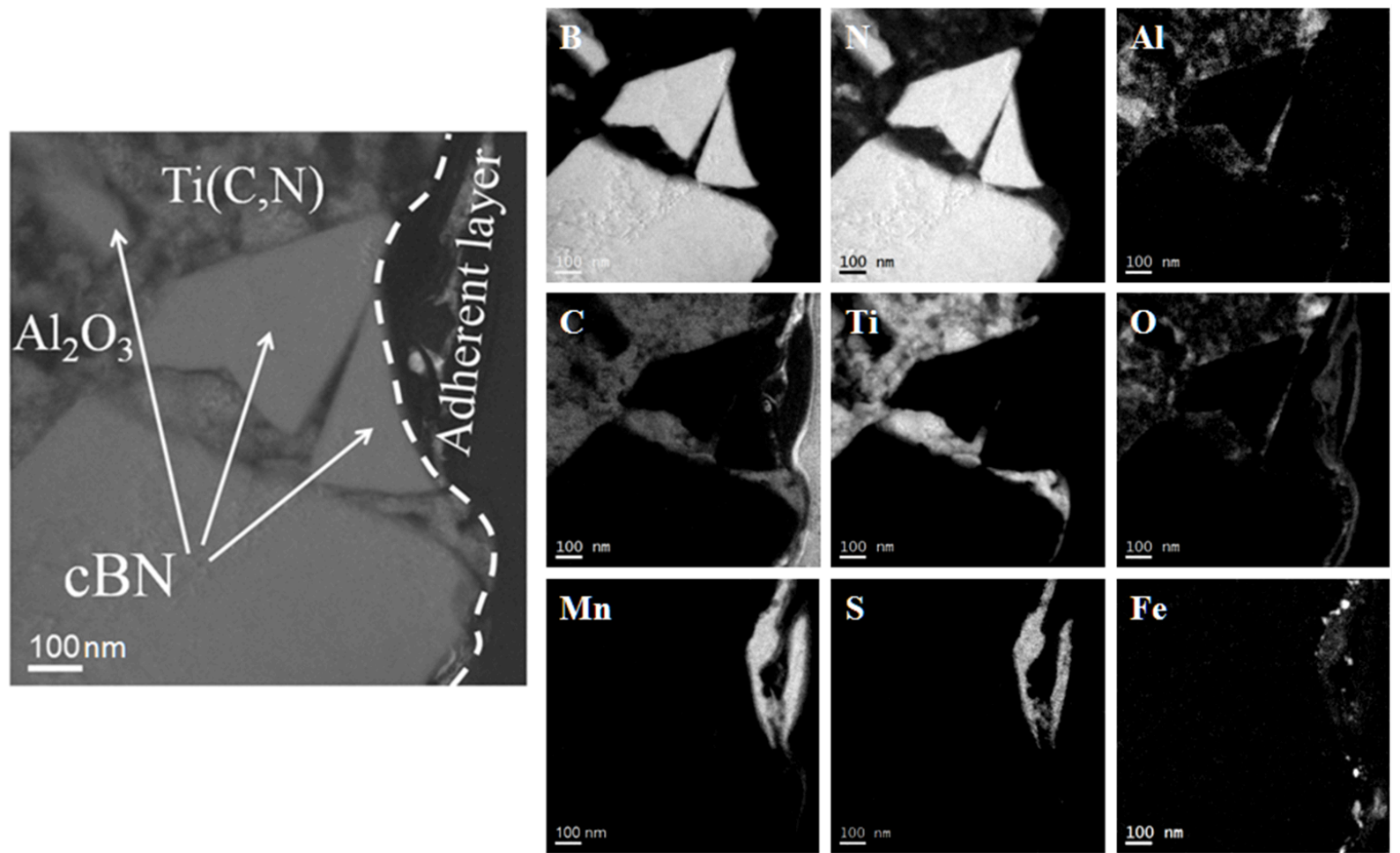

Figure 4. Some phases are indicated in the combined TEM/EFTEM image, to the left, as well as the wear surface towards the adherent layer. The EFTEM elemental maps, to the right, are from a PCBN insert run in workpiece material A (high sulphur content) for B (K-edge), C (K-edge), O (K-edge), Mn ( $\mathrm{L}_{2,3}$-edge), Al (Kedge), $\mathrm{N}$ (K-edge), Ti ( $\mathrm{L}_{2,3}$-edge), $\mathrm{Fe}\left(\mathrm{L}_{2,3}\right.$-edge) and $\mathrm{S}\left(\mathrm{L}_{2,3}\right.$-edge $)$. A large $\mathrm{Mn}$ and $\mathrm{S}$ area can be seen in the $\mathrm{Mn}$ and $\mathrm{S}$ elemental maps. The wear surface of the $\mathrm{cBN}$ grains in the centre show a concave shape seen in the $\mathrm{B}$ and $\mathrm{N}$ elemental maps. See figure 8 a for a mixed colour map of this area. 

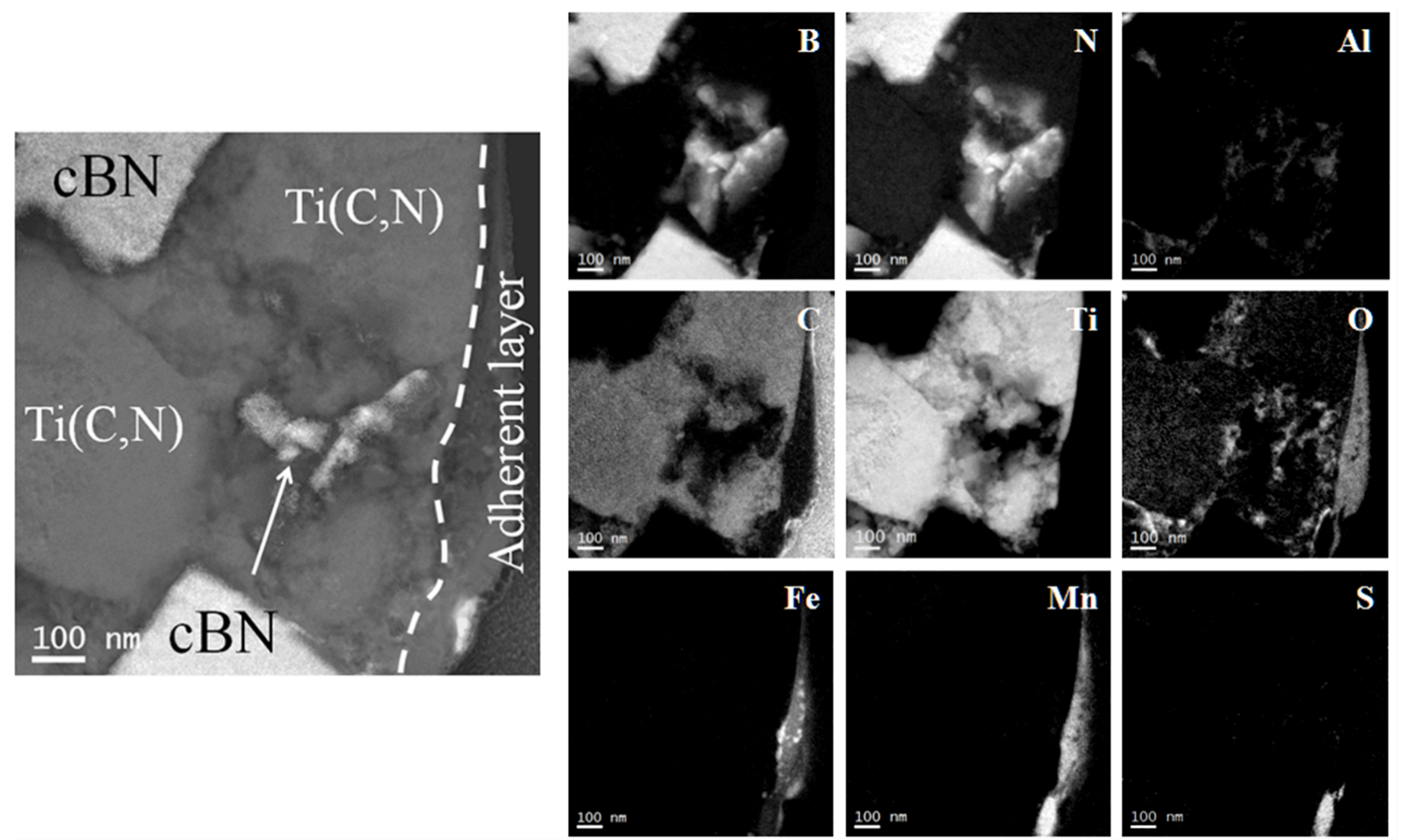

Figure 5. Some phases are indicated in the combined TEM/EFTEM image, to the left, as well the wear surface towards the adherent layer. A part of the protective Pt-layer is visible along the right edge of the micrograph as the darker phase. The EFTEM elemental maps, to the right, are from a PCBN insert run in workpiece material A (high sulphur content) for B (K-edge), C (K-edge), O (K-edge), Mn ( $\mathrm{L}_{2,3}$-edge), Al (K-edge), N (K-edge), Ti $\left(\mathrm{L}_{2,3}\right.$-edge), $\mathrm{Fe}\left(\mathrm{L}_{2,3}\right.$-edge) and $\mathrm{S}\left(\mathrm{L}_{2,3}\right.$-edge). The elemental maps for $\mathrm{Fe}$ and $\mathrm{O}$ show a larger Fe-rich feature which is oxidised on the surface. This area also contains Mn which is seen in the Mn elemental map. The Ti elemental map shows what a typical $\mathrm{Ti}(\mathrm{C}, \mathrm{N})$ wear surface looks like, flat or even with a convex tendency in shape. See figure $8 b$ for a mixed colour map of this area.
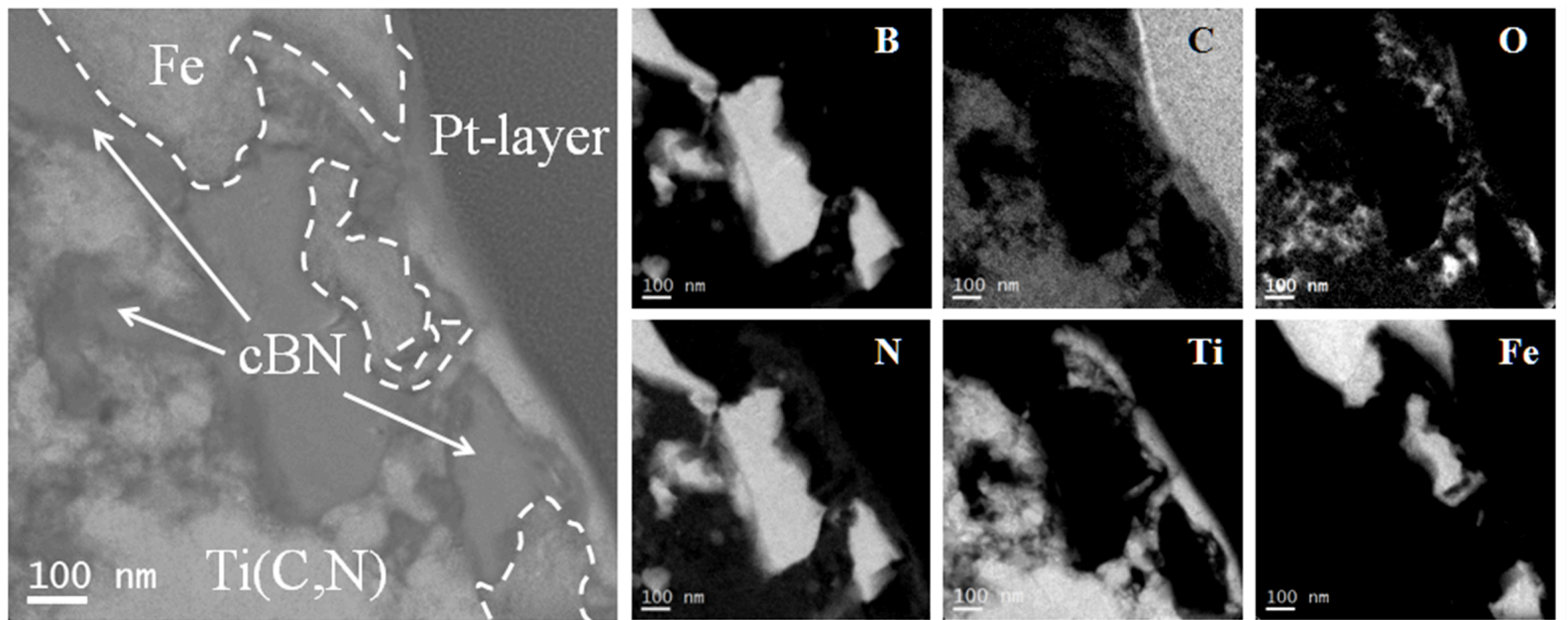

Figure 6. Some phases are indicated in the combined TEM/EFTEM micrograph, to the left. Adhered material (Fe-rich compounds) is visible as island-like features inside the PCBN tool material, marked in the micrograph. EFTEM elemental maps from a PCBN insert run in workpiece material B (low sulphur content) for B (K-edge), $\mathrm{C}$ (K-edge), $\mathrm{O}$ (K-edge), $\mathrm{N}$ (K-edge), Ti ( $\mathrm{L}_{2,3}$-edge) and $\mathrm{Fe}\left(\mathrm{L}_{2,3}\right.$-edge). cBN grains which are attacked by a ironrich feature can be seen in the B and $\mathrm{N}$ elemental maps. See figure $8 c$ for a mixed colour map of this area. 

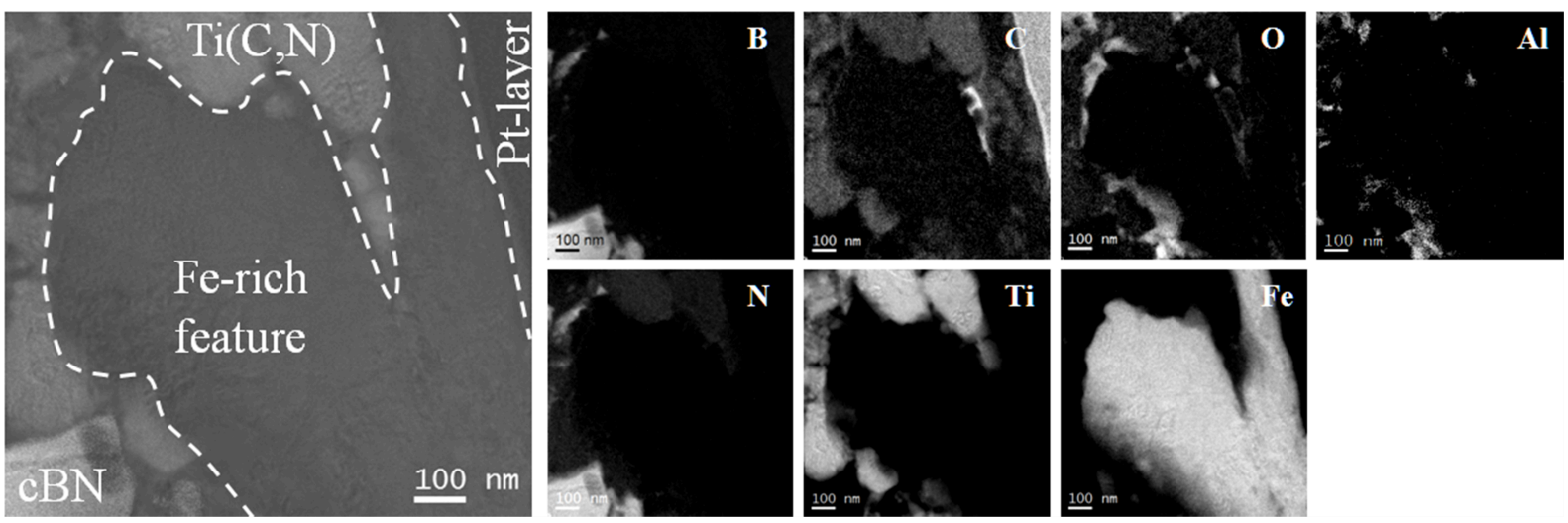

Figure 7. Some phases are indicated in the combined TEM/EFTEM micrograph, to the left. Adhered material (Fe-rich compounds) is visible as island-like features inside the PCBN tool material, marked in the micrograph. EFTEM elemental maps from a PCBN insert run in workpiece material B (low sulphur content) for B (K-edge), $\mathrm{C}$ (K-edge), $\mathrm{O}$ (K-edge), $\mathrm{Al}$ (K-edge), $\mathrm{N}$ (K-edge), Ti ( $\mathrm{L}_{2,3}$-edge) and $\mathrm{Fe}\left(\mathrm{L}_{2,3}\right.$-edge).
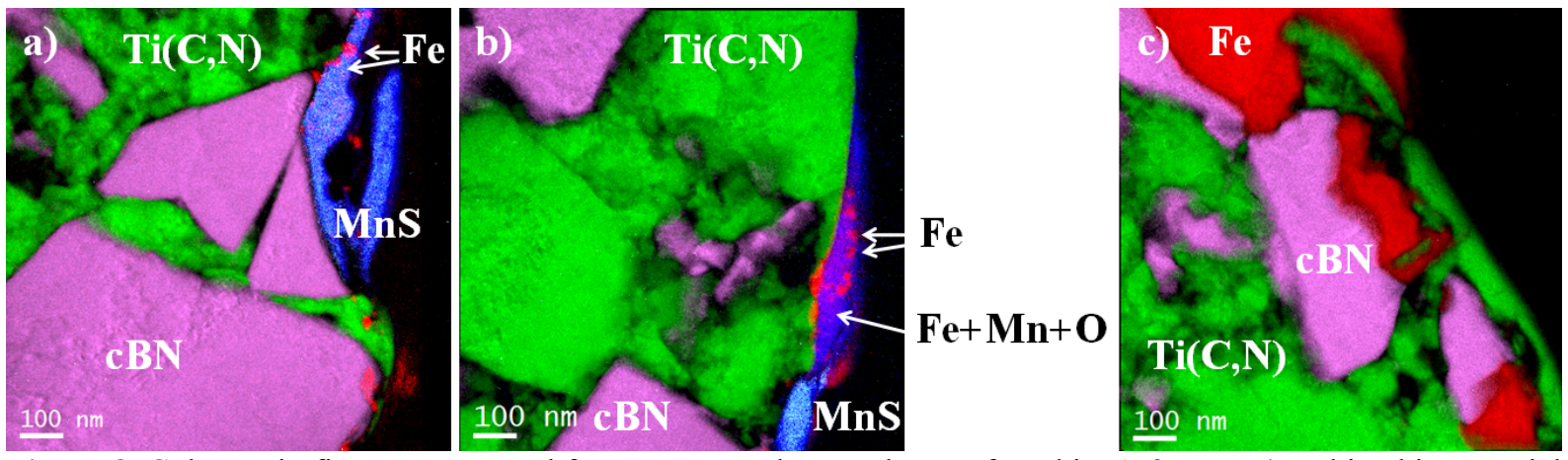

Figure 8. Colour mix figures composed from EFTEM elemental maps found in a) figure 4 (machined in material A - high sulphur content) b) figure 5 (machined in material A - high sulphur content) c) figure 6 (machined in material B - low sulphur content). 